\title{
A comprehensive, non-invasive visualization of primordial germ cell development in mice by the Prdm1-mVenus and Dppa3-ECFP double transgenic reporter
}

\author{
Yasuhide Ohinata ${ }^{1}$, Mitsue Sano ${ }^{1,2}$, Mayo Shigeta ${ }^{1}$, Kaori Yamanaka ${ }^{1}$ and Mitinori Saitou ${ }^{1,3}$ \\ ${ }^{1}$ Laboratory for Mammalian Germ Cell Biology, RIKEN Kobe Institute, Center for Developmental Biology, 2-2-3 \\ Minatojima-Minamimachi, Chuo-ku, Kobe 650-0047, Japan, ${ }^{2}$ Department of Biosystems Science, Graduate School of \\ Science and Technology, Kobe University, 1-1 Rokkodai-cho, Nada-ku, Kobe 657-8501, Japan and ${ }^{3}$ Laboratory of \\ Molecular Cell Biology and Development, Graduate School of Biostudies, Kyoto University, Yoshida-Konoe-cho, \\ Sakyo-ku, Kyoto 606-8501, Japan
}

Correspondence should be addressed to M Saitou; Email: saitou@cdb.riken.jp

Y Ohinata and M Sano contributed equally to this work

\begin{abstract}
The ability to monitor the development of a given cell lineage in a non-invasive manner by fluorescent markers both in vivo and in vitro provides a great advantage for the analysis of the lineage of interest. To date, a number of transgenic or knock-in mouse strains, in which developing germ cells are marked with fluorescent reporters, have been generated. We here describe a novel double transgenic reporter mouse strain that expresses membrane-targeted Venus (mVenus), a brighter variant of yellow fluorescent protein (YFP), under the control of Prdm1 (Blimp1) regulatory elements and enhanced cyan fluorescent protein (ECFP) under the control of Dppa3 (Stella/Pgc7). The double transgenic strain unambiguously marked Prdm1 expression in the lineage-restricted precursors of primordial germ cells (PGCs) in the proximal epiblast at embryonic day (E) 6.25 and specifically illuminated Prdm1- and Dppa3-positive migrating PGCs after E8.5. The double transgenic reporter also precisely recapitulated dynamic embryonic expression of Prdm1 outside the germ cell lineage. Moreover, we derived ES cells that bore both transgenes. These cells made a robust contribution both to the germ and somatic cell lineages in chimeras with accurate Prdm1-mVenus and Dppa3-ECFP expression. The transgenic strain and the ES cells will serve as valuable experimental materials not only for analyzing the origin and properties of the germ cell lineage in vivo, but also for establishing a culture system to efficiently induce proper germ cells with temporally coordinated Prdm1 and Dppa3 expression in vitro.

Reproduction (2008) 136 503-514
\end{abstract}

\section{Introduction}

The germ cell lineage is the only source for the creation of new organisms in most multicellular animals, ensuring the perpetuation of the genetic and epigenetic information across generations. In mice, and presumably all mammals, germ cell fate is a property induced during development, rather than a trait inherited from the egg, as seen in some model organisms (Ohinata et al. 2006, Seydoux \& Braun 2006, Hayashi et al. 2007). Accordingly, specification of germ cell fate has been an active area of research, with great relevance to stem cell biology and epigenetics.

Recent studies have shown that germ cell fate in mice is induced in proximal epiblast cells by bone morphogenetic protein (BMP) signals from extraembryonic tissues (Lawson et al. 1999, Ying et al. 2000, Chang \& Matzuk 2001, Tremblay et al. 2001, Ying \& Zhao 2001,
Hayashi et al. 2002, Chu etal.2004) at around embryonic day (E) 6.25 as those expressing PRDM1 (previously known as BLIMP1; Ohinata et al. 2005, Vincent et al. 2005), a potent transcriptional regulator involved in cell fate specification in diverse developmental contexts (Turner et al. 1994, de Souza et al. 1999, Shapiro-Shelef et al. 2003, Baxendale et al. 2004, Roy \& Ng 2004, Hernandez- Lagunas et al. 2005, Wilm \& Solnica-Krezel 2005, Horsley et al. 2006, Kallies et al. 2006, Martins et al. 2006, Magnusdottir et al. 2007, Robertson et al. 2007). These Prdm1-expressing cells increase in number and, at around E7.25, exclusively go on to form primordial germ cells (PGCs), the primary source of both oocytes and spermatozoa, with characteristic alkaline phosphatase activity (Chiquoine 1954, Ginsburg et al. 1990) and Dppa3 (previously known as Stella or Pgc7) expression (Saitou et al. 2002, Sato et al. 2002). The Prdm1- and Dppa3-positive PGCs repress Hox gene 
expression (Saitou et al. 2002, Yabuta et al. 2006), regain potential pluripotency (Matsui et al. 1992, Yabuta et al. 2006), and initiate migration, with concomitant genomewide epigenetic reprogramming (Seki et al. 2005, 2007), toward embryonic gonads where they eventually differentiate into functional gametes. PRDM1 expression continues in PGCs until around E13.5 in both sexes (Chang et al. 2002), whereas DPPA3 is maintained until around E15.5 in males and around E13.5 in females (Sato et al. 2002). DPPA3 expression resumes specifically in the primordial follicle stage oocytes in new born females and continues to be expressed throughout oocyte development (Sato etal. 2002, Payer etal. 2003). DPPA3 is also expressed zygotically from the two-cell stage until around E4.5 (Sato et al. 2002, Payer et al. 2003) and then is exclusively regained in Prdm1-expressing cells at around E7.25.

To date, transgenic reporter strains expressing enhanced green fluorescent protein (EGFP) under the control of Prdm1 or Dppa3 upstream elements (Blimp1mEGFP or stella-EGFP) have been generated (Ohinata et al. 2005, Payer et al. 2006). These strains have been useful to monitor the origin and development of the germ cell lineage in vivo and are considered to surpass reporter strains based on other genes (MacGregor et al. 1995, Yeom et al. 1996, Yoshimizu et al. 1999, Anderson et al. 2000, Toyooka et al. 2003, Tanaka et al. 2004) in terms of their early onset of expression and germ line specificity (Payer et al. 2006). Moreover, the ES cells derived from these strains are expected to be excellent tools to monitor the efficient generation of PGCs and their subsequent development in vitro (Payer et al. 2006), which will provide abundant experimental materials and may serve as a critical basis for future regenerative medicine applications. However, both strains have some disadvantages. The Blimp1-mEGFP strain precisely recapitulates $\mathrm{Prdm} 1$ expression in vivo and shows expression in the germ line as early as E6.25 (Ohinata et al. 2005). However, endogenous Prdm1 expression is not restricted to the germ line but is more widespread, especially after E7.5 (Chang et al. 2002, Vincent et al. 2005, Robertson et al. 2007). The stella-EGFP strain exhibits specific expression of EGFP in PGCs but only after E7.5, and is therefore not useful for detecting PGC precursors or monitoring the process of PGC specification (Payer et al. 2003, 2006).

To circumvent these drawbacks, we generated a transgenic reporter strain that expresses membranetargeted Venus (mVenus), a brighter variant of YFP (Nagai et al. 2002), under the control elements of Prdm1 and another strain that express ECFP under the control of Dppa3. (We also generated strains that express Venus under the control of Dppa3.) By crossing these strains, we obtained a double transgenic reporter strain that homozygously bears both Prdm1-mVenus and Dppa3ECFP (Blimp1-mVenus and stella-ECFP, BVSC). We report here that the BVSC strain faithfully recapitulates endogenous Prdm1 and Dppa3 expression, thereby enabling the specific real-time monitoring of the development of the germ cell lineage from its incipience. Moreover, we established an ES cell line bearing the BVSC transgenes, which will serve as a useful experimental tool for establishing an in vitro culture system reliably generating germ cells from ES cells.

\section{Results \\ Generation of Prdm1-mVenus, Dppa3-ECFP, and Dppa3-Venus transgenic mice}

To generate a transgenic strain that simultaneously marks the expression of Prdm1 and Dppa3 with two different colors, we decided to use Venus and ECFP for monitoring Prdm1 and Dppa3 respectively. The Prdm1mVenus bacterial artificial chromosome (BAC) construct, spanning a total of $\sim 230 \mathrm{~kb}(\sim 140 \mathrm{~kb}$ upstream of the $\operatorname{Prdm} 1$ transcription start site), bears Venus targeted to and anchored in the plasma membrane by the Igк leader and platelet-derived growth factor receptor (PDGFR) transmembrane sequences respectively, after the initial in-frame ATG of the exon 3 of the Prdm1 gene (Fig. 1A). This construct is thus identical to the Blimp1-mEGFP transgene reported previously (Ohinata et al. 2005), except that EGFP is replaced by Venus. The Dppa3-ECFP construct includes $\sim 16 \mathrm{~kb}$ upstream of the Dppa3 gene and bears ECFP followed by an SV40 polyadenylation sequence recombined in the exon 2 of Dppa3 in a framematched manner, as well as the downstream $\sim 1.3 \mathrm{~kb}$ sequence up to exon 4 (Fig. 1A). We also generated a Dppa3-Venus construct. These transgenic constructs for Dppa3 do not bear any neighboring genes, such as Gdf3, Apobec1, and Nanog, which could influence the germ cell development if overexpressed from the transgenes.

We generated 8, 11, and 3 independent strains for Prdm1-mVenus, Dppa3-ECFP, and Dppa3-Venus strains respectively, by pronuclear injection of the transgenes. Three of the Prdm1-mVenus lines showed apparently correct Prdm1 expression patterns, and we decided to use the strain that exhibited the brightest expression for subsequent analysis. The Dppa3-ECFP and Dppa3-Venus strains (4 out of 11 and 3 out of 3 respectively) also showed specific expression of ECFP and Venus respectively, and we decided to use the ones that exhibited earlier and brighter expression in the developing PGCs for further analysis. We determined the chromosomal localizations of the transgenes by FISH analysis, which revealed that the selected $\mathrm{Prdm} 1$-mVenus strain harbors the transgene on the $\mathrm{A} 1-\mathrm{A} 2$ region of the chromosome 2, and the Dppa3-ECFP and Dppa3-Venus strains bear the transgenes on the M5 region of the chromosome 1 and the $\mathrm{C} 1$ region of the chromosome 19 respectively (Fig. 1B, data not shown).

We performed several generations of matings between the Prdm1-mVenus and the Dppa3-ECFP strains to obtain the double homozygous strain (BVSC). We 
Prdm1 locus
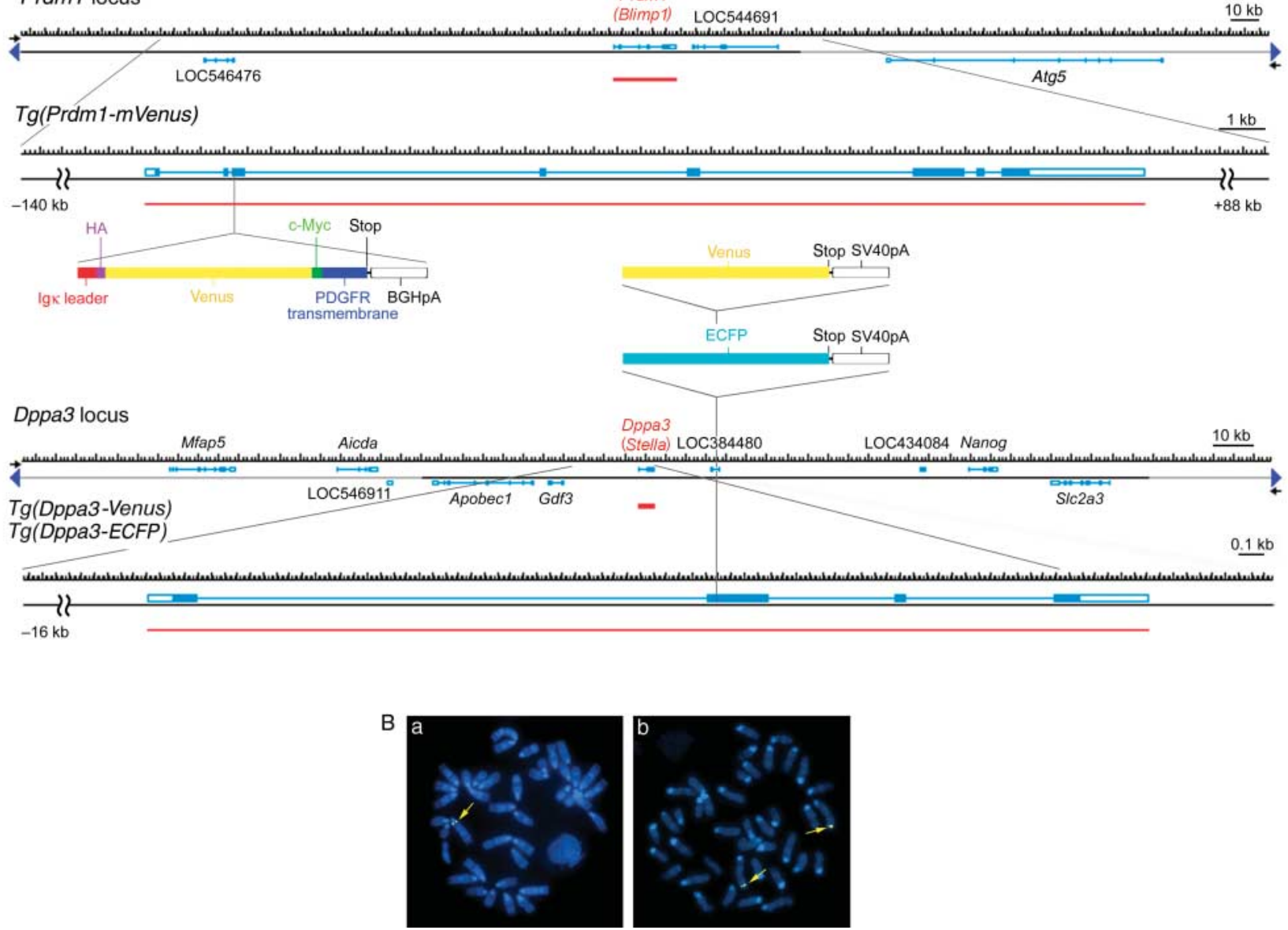

Figure 1 Prdm1-mVenus, Dppa3-ECFP, and Dppa3-Venus transgenes. (A) Schematic of the Prdm1-mVenus, Dppa3-ECFP, and Dppa3-Venus transgenes. The genomic loci and exon-intron structures of the Prdm1 and Dppa3 genes are shown. The positions at which sequences of the fluorescent reporters are recombined are also shown. The membrane-targeted Venus construct includes an Igк leader sequence, an epitope of hemagglutinin antigen, a Venus coding sequence, an epitope of c-myc, and the transmembrane sequence of the PDGF receptor of the pDisplay vector (Invitrogen). (B) Chromosomal localization of the (a) Prdm1-mVenus and (b) Dppa3-ECFP transgenes. The Prdm1-mVenus transgenes are on the A1-A2 region of chromosome 2 and the Dppa3-ECFP transgenes are on the M5 region of chromosome 1 (yellow arrows). FISH analyses were performed using the chromosome spreads of splenocytes from a (a) Prdm1-mVenus heterozygous mouse or (b) Dppa3-ECFP homozygous mouse.

crossed the double homozygous candidates with nontransgenic mice and judged the candidates as double homozygous when all the embryos or offspring from at least two litters showed expression of both transgenes. Thereafter, the double homozygous mice were maintained by intermating.

\section{BVSC expression in pre-implantation and early post-implantation embryos}

We first determined the expression of the BVSC transgenes in pre-implantation (Fig. 2A) and early postimplantation embryos (Fig. 2B) from matings between the BVSC males and non-transgenic females. As expected from the previous finding that Dppa3 expression from the paternal allele is initiated as early as the two-cell stage concomitant with the onset of bulk zygotic transcription (Payer et al. 2003, 2006), we detected strong expression of the Dppa3-ECFP transgene in the morula stage embryos (Fig. 2A). In the early blastocyst stage, the embryos at E3.5, the Dppa3-ECFP expression was very strong in the inner cell mass (ICM) cells as well as in the trophectoderm (Fig. 2A). Prdm1mVenus expression was barely detectable in these preimplantation embryos. In peri-implantation embryos at E4.5, we observed relatively weak expression of Dppa3ECFP in all the embryonic and extraembryonic cells, whereas, notably, we detected specific expression of Prdm1-mVenus in the incipient primitive endoderm (Fig. 2A). At E5.5, we still observed weak Dppa3-ECFP expression throughout the embryos, which was probably attributable to residual ECFP activity from earlier embryos. By contrast, Prdm1-mVenus expression was specifically detected in the visceral endoderm (VE) cells (Fig. 2B). At E6.5, there seemed almost no expression of Dppa3-ECFP, while we detected Prdm1-mVenus expression in the embryonic part of the VE and, most importantly, in a number of the most proximal epiblast 

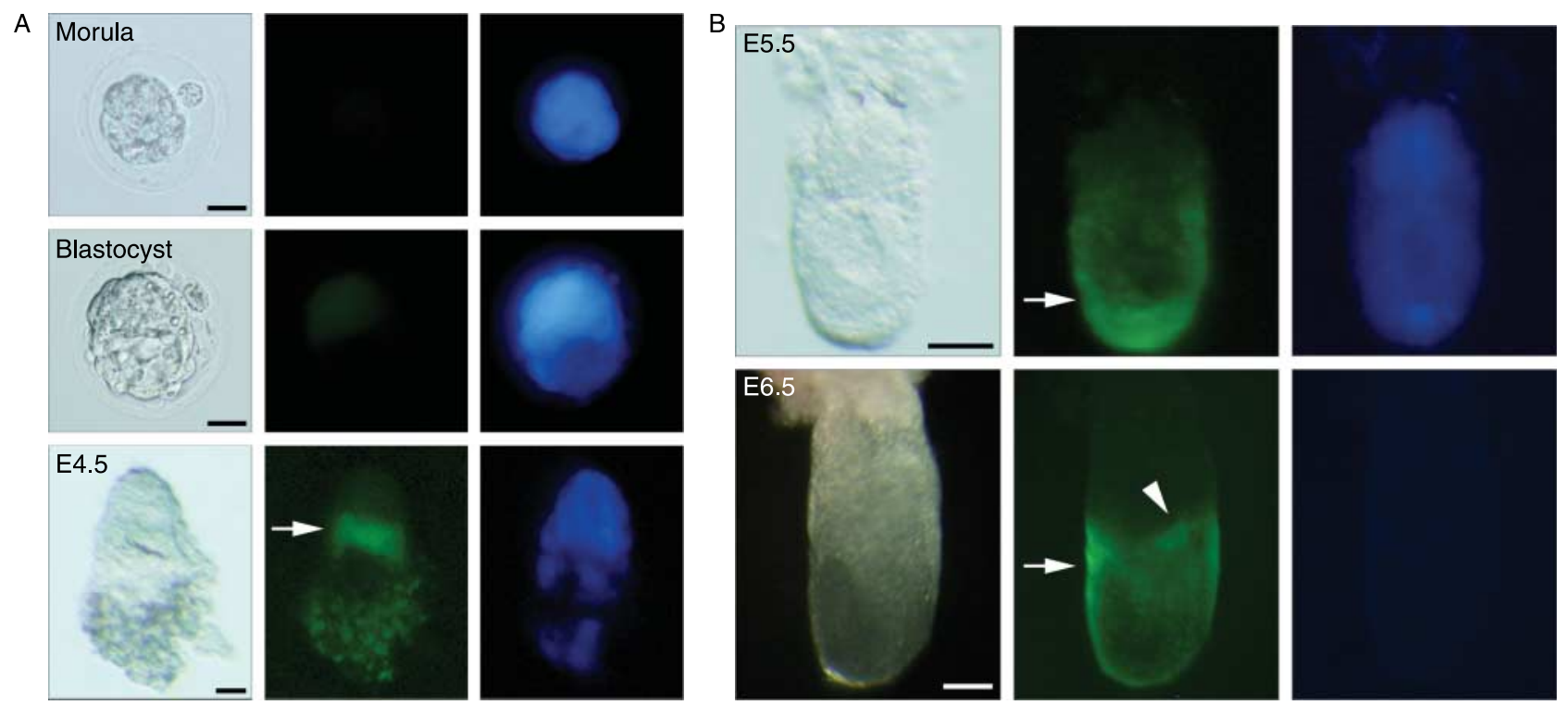

Figure 2 Expression of the BVSC transgenes in pre- and early post-implantation embryos. (A) BVSC expression in pre-implantation embryos. BVSC expression in a morula (top row), a blastocyst (middle row), and an E4.5 embryo (bottom row) are shown with bright field images in the left column, Prdm1-mVenus expression in the middle column, and Dppa3-ECFP expression in the right column. An arrow indicates Prdm1-mVenus expression in the incipient primitive endoderm. Bars, $25 \mu \mathrm{m}$. (B) BVSC expression in post-implantation embryos. BVSC expression in an E5.5 embryo (top row) and an E6.5 embryo (bottom row) are shown with bright field images in the left column, Prdm1-mVenus expression in the middle column, and Dppa3-ECFP expression in the right column. Arrows indicate Prdm1-mVenus expression in the visceral endoderm and an arrowhead indicates Prdm 1-mVenus in most proximal epiblast cells, most likely, the lineage-restricted PGC precursors. The bar at the top of the figure indicates 50 $\mu$, and that at the bottom indicates $100 \mu \mathrm{m}$.

cells, which most likely correspond to the emerging precursors of PGCs (Fig. 2B, see below) (Ohinata et al. 2005). The Dppa3-Venus and Dppa3-ECFP transgenes showed essentially identical expression in early embryos (data not shown). These observations demonstrate that the BVSC transgenes recapitulate endogenous expression of Prdm1 and Dppa3 faithfully, although both fluorescent markers, especially Dppa3-ECFP, seemed perhaps more stable than the endogenous proteins (see Discussion). It has also become evident that Prdm1 and Dppa3, two early markers of the PGCs (Saitou et al. 2002, Sato et al. 2002, Ohinata et al. 2005, Vincent et al. 2005), exhibited highly different expression patterns prior to PGC specification, indicating that the expressions of these two genes are under essentially distinct regulations.

\section{Embryonic expression of Prdm1-mVenus outside the germ cell lineage}

We next went on to define the expression of Prdm1mVenus outside the germ cell lineage after E7.5 at the whole-mount resolution (Fig. 3A). Prdm1 has been shown to be critical in the specification of diverse cell lineages both in developing embryos and adults (Turner et al. 1994, de Souza et al. 1999, Shapiro-Shelef et al. 2003, Baxendale et al. 2004, Roy \& Ng 2004, Hernandez-Lagunas et al. 2005, Wilm \& Solnica-Krezel 2005, Horsley et al. 2006, Kallies et al. 2006, Martins et al. 2006, Magnusdottir et al. 2007, Robertson et al. 2007), and a transgenic reporter strain faithfully recapitulating its entire expression should be of general use. At E7.5, as in E6.5 embryos, we detected Prdm1mVenus expression in VE and PGCs (see also below). In addition, Prdm1-mVenus was observed in the anterior axial mesendoderm region, which would include the anterior definitive endoderm and prechordal plate (Vincent et al. 2005). At E8.5, Prdm1-mVenus was lost from the midline, and we observed a prominent expression of Prdm1-mVenus in the anterolateral definitive endoderm, most strongly in the region from which the branchial arch will emerge (Vincent et al. 2005). At E9.5, we detected Prdm1-mVenus in many parts of the embryo: it was observed in a region of the ventral forebrain, in the pharyngeal endoderm of the first branchial arch, more broadly in the more caudal region from which the second and third arches will emerge, in the otic vesicles, very strongly throughout the mesenchyme of the incipient forelimb and hind limb buds, throughout the gut endoderm, and in the myotome of the most rostal somites, which is the site where myogenesis initiates (reviewed by Tajbakhsh \& Buckingham (2000)). At E10.5, Prdm1-mVenus expression in the branchial arch region seemed substantially down-regulated, whereas it was strongly expressed in the myotome compartment of the somites. We also detected Prdm1mVenus in the intersegmentary arteries between the somites and in the endothelial cells of the superficial 
A
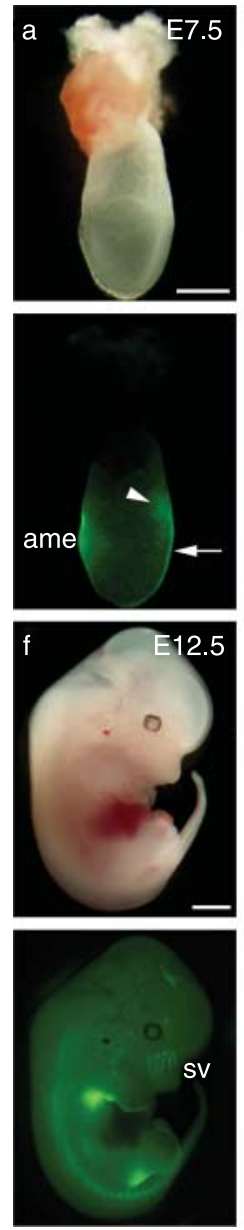

B

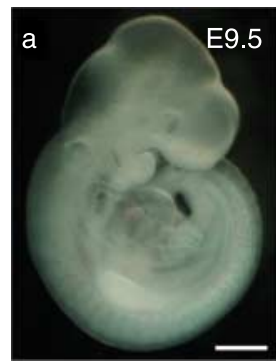

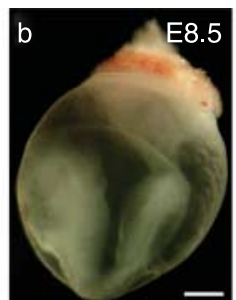
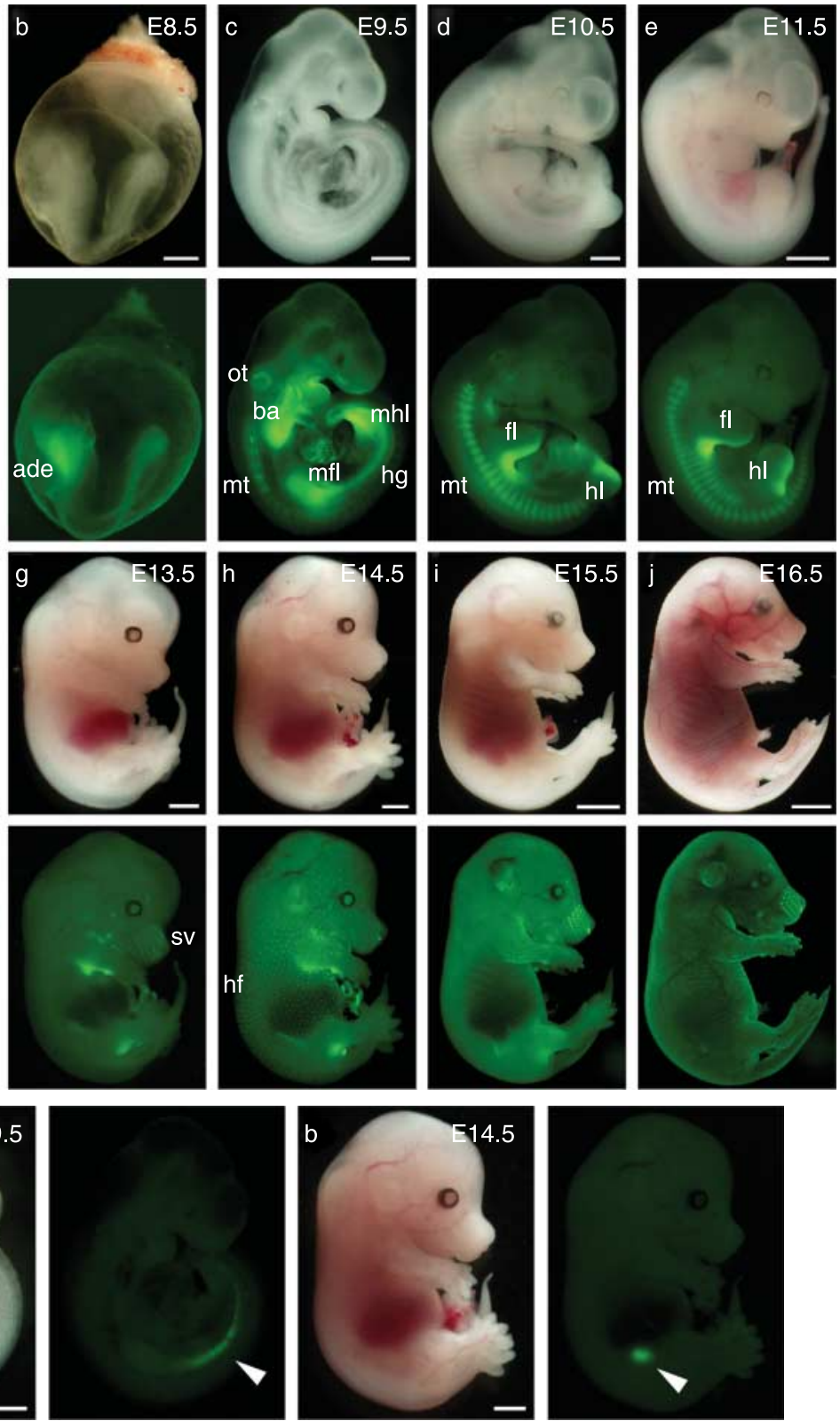

capillaries (data not shown, Fig. 4B). The expression of Prdm1-mVenus in the limb bud seemed to become restricted to the posterior region encompassing the zone of polarizing activity (ZPA) and to the apical ectodermal ridges (AER). At E11.5, we detected Prdm1-mVenus more strongly in the myotome of more caudal somites and in the ZPA and AER of both limb buds. At E12.5, Prdm1-mVenus began to be expressed in the mesenchyme of the emerging sensory vibrissae, and at E14.5, it began to be expressed in the mesenchyme forming the dermal papillae of the hair follicles of the coat region. All these expression domains of Prdm1-mVenus are essentially in good agreement with those of Prdm1 mRNA and protein expression previously demonstrated by in situ hybridization and immunohistochemistry (Chang et al. 2002, Vincent et al. 2005, Robertson et al. 2007). Thus, these observations demonstrate that Prdm1-mVenus monitors the dynamic embryonic expression of endogenous Prdm1 with remarkable precision.

\section{BVSC expression in the germ cell lineage}

We next determined the expression of BVSC in the germ cell lineage. At E6.5 just after the onset of gastrulation, we detected the expression of Prdm1-mVenus in a subset of POU5F1-positive most proximal epiblast cells that are considered to be the lineage-restricted precursors of PGCs (Ohinata et al. 2005) (Fig. 4Aa). At E7.5, 
A

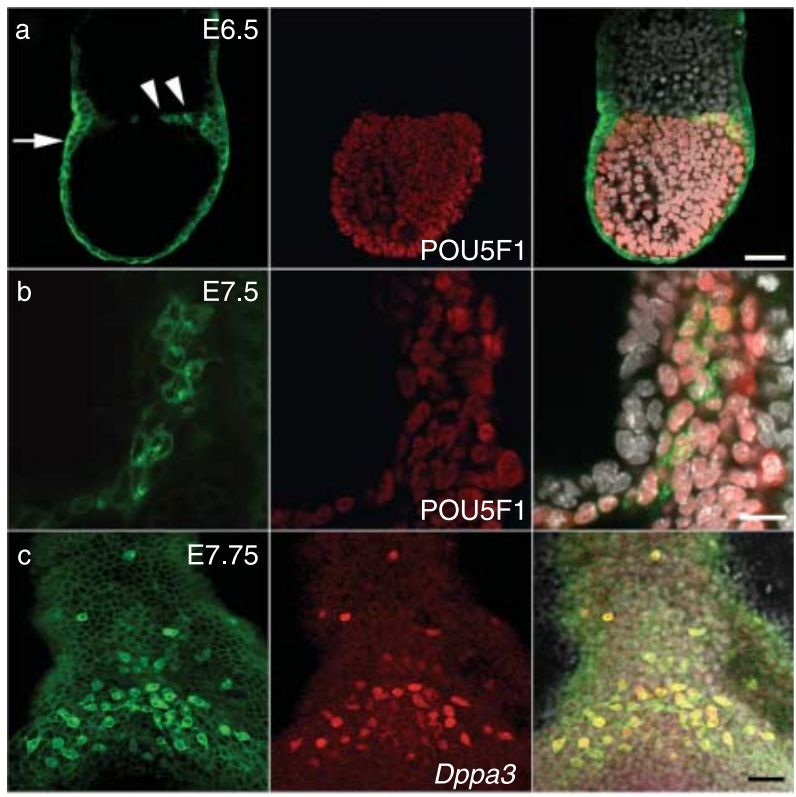

B

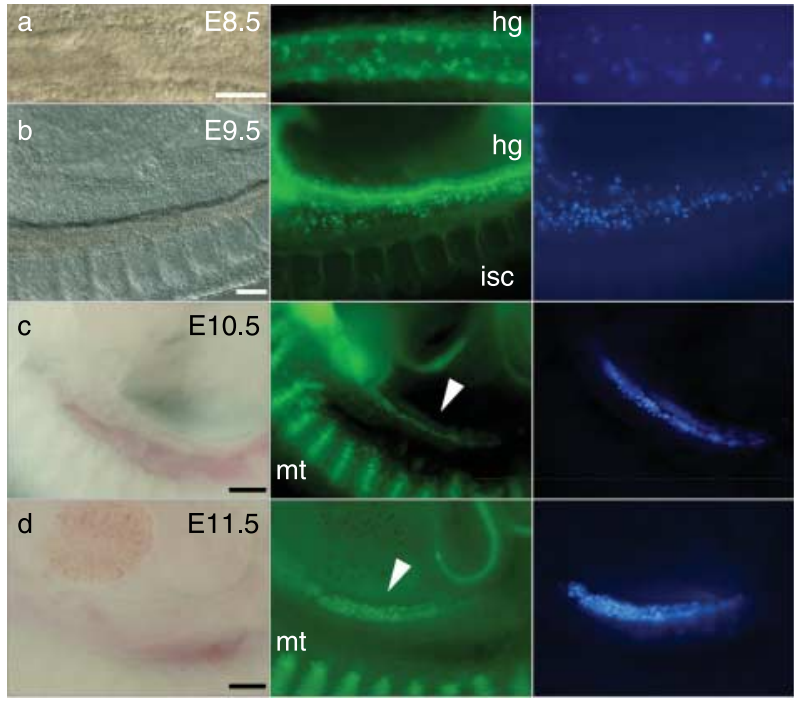

C

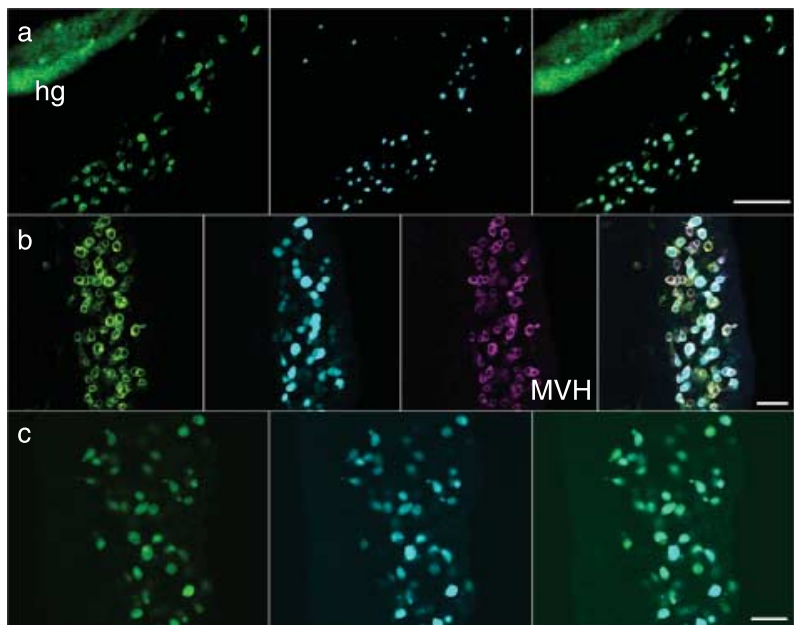

Figure 4 (continued) 

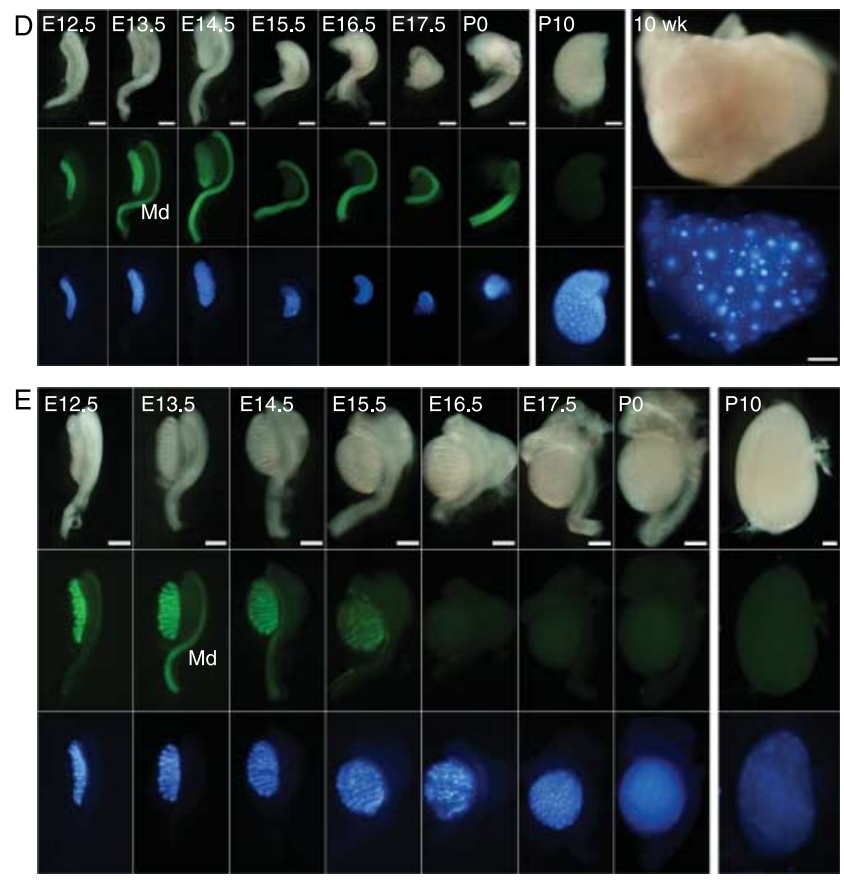

Figure 4 Expression of the BVSC transgenes in the germ cell lineage. (A) Expression of Prdm1-mVenus (left column) and POU5F1 (middle column) in (a) E6.5 and (b) E7.5 embryos, and expression of Prdm1-mVenus (left column) and DPPA3 (middle column) in (c) E7.75 embryos. Merged images are shown on the right. Arrowheads in (a) indicate Prdm1-positive presumable lineage-restricted PGC precursors and an arrow indicates the visceral endoderm. Cells expressing Prdm1-mVenus at a weaker level and negative for DPPA3 in (c) are visceral endoderm cells. Bar in (a and c), $50 \mu \mathrm{m}$; in (b), $20 \mu \mathrm{m}$. (B) Expression of the BVSC transgenes in the region where PGCs reside at (a) E8.5, (b) E9.5, (c) E10.5 and (d) E11.5 with bright field images in the left column, Prdm1-mVenus expression in the middle column, and Dppa3-ECFP expression in the right column. Arrowheads in (c and d) indicate the nascent genital ridges. hg, hindgut; isc, intersegmentary capillary; mt, myotome. Bars, $50 \mu \mathrm{m}$. (C) Co-expression of BVSC in the mesentery at E9.5 (a) and genital ridge at E11.5 (b), and co-expression of Dppa3-ECFPand Dppa3-Venus in the genital ridge at E11.5 (c), with Prdm1mVenus (a, b) or Dppa3-Venus (c) expression in the left column, and Dppa3-ECFP expression in the second-left column. Merged images are shown on the right. BVSC-positive cells at E11.5 were positive for mouse vasa homologue (MVH) (b, second-right, magenta). hg, hindgut. Bar in (a), $100 \mu \mathrm{m}$; in (b), $25 \mu \mathrm{m}$; in (c), $25 \mu \mathrm{m}$. (D) Expression of the BVSC transgenes in the developing ovaries (from E12.5 to P (postnatal day) 0 , and P10 and 10 wk (10 weeks old)) with bright field images in the top row, Prdm1-mVenus expression in the middle row (except the 10-week column), and Dppa3-ECFP expression at the bottom row. Dppa3-ECFP shows specific expression in oocytes of various developmental stages in an ovary of 10-week-old female. Md, Müllerian duct. Bars in the E12.5-P0 columns, $150 \mu \mathrm{m}$; in the P10 column, $100 \mu \mathrm{m}$; in the $10 \mathrm{wk}$ column, $200 \mu \mathrm{m}$. (E) Expression of the BVSC transgenes in the developing testes (from E12.5 to P0 and P10) with bright field images in the top row, Prdm1-mVenus expression in the middle row, and Dppa3-ECFP expression in the bottom row. Md, Müllerian duct. Bars, $150 \mu \mathrm{m}$.

Prdm1-mVenus was detected in a cluster of cells at the border between the embryonic and extraembryonic mesoderm, contiguous from the most proximal epiblast (Fig. 4Ab). These cells are considered to include the founding PGC population (Ohinata et al. 2005). At E7.75, Prdm1-mVenus strong-positive cells that migrated into the endoderm showed robust endogenous DPPA3 expression (Fig. 4Ac; Saitou et al. 2002, Yabuta et al. 2006, Seki et al. 2007), indicating that Prdm1-mVenus expression indeed marks the emerging PGC population. We did not detect Dppa3-ECFP expression at this stage. At E8.5, Prdm1-mVenus was detected in the cells apparently migrating in the hindgut endoderm, which also began to show Dppa3-ECFP expression (Fig. 4Ba). At E9.5, we again detected robust BVSC co-expression in the cells in the hindgut, many of which seemed to have already left the endoderm and to be moving through the mesentery toward the developing genital ridges (Fig. 4Bb and $\mathrm{Ca}$ ). At both E10.5 and E11.5, we found strong BVSC expression in the cells in the incipient genital ridges (Fig. 4BC and d). Immunofluorescence analysis showed that the BVSC-expressing cells in the E11.5 genital ridges were exclusively positive for $M \mathrm{MH}$, one of the wellrecognized germ cell markers (Fig. 4Cb) (Tanaka et al. 2000, Toyooka et al. 2000), demonstrating that BVSCpositive cells were indeed PGCs. From E12.5 onward, the genital ridges had a sexually dimorphic appearance (reviewed by Capel 2000), and we could easily distinguish the sex of the embryos. In the female genital ridges, Prdm1-mVenus showed strong expression until E13.5 and was down-regulated acutely at E14.5 in an anterior-to-posterior order (Fig. 4D). We did not detect Prdm1-mVenus in female germ cells, thereafter. We also detected strong Dppa3-ECFP expression until E13.5, after which it became somewhat weaker from the entire female genital ridges. However, we consistently observed some level of Dppa3-ECFP fluorescence, which was probably attributable to the higher stability 
of ECFP (see Discussion). The neonatal ovaries that contain oocytes of the primordial follicle stage (Pepling 2006), re-initiated strong Dppa3-ECFP expression, which persisted thereafter in the developing oocytes (Fig. 4D). In the male genital ridges, we also detected strong Prdm1-mVenus expression until E13.5. Similar to the expression in the female germ cells, Prdm1-mVenus became down-regulated after E14.5 in an anteriorto-posterior order, and we did not detect Prdm1-mVenus in the male germ cells after E16.5. The Dppa3-ECFP transgene continued to robustly mark male germ cells until E16.5, after which it gradually became weaker. We did not detect Dppa3-ECFP in the adult testis (data not shown). The Dppa3-Venus transgenic strains also recapitulated Dppa3 expression specifically in the germ cell lineage after E8.0 and exhibited precise co-expression with Dppa3-ECFP in the genital ridge at E11.5 (Figs 3B and 4CC, data not shown). Interestingly, we also noted that Prdm1-mVenus was expressed in the Müllerian duct but not in the Wolffian duct at E13.5 both in the females and males, and it continued to be expressed in the Müllerian duct up until at least postnatal day 0 in the female embryos, but disappeared after E14.5 in the males, in which the Müllerian duct itself degenerates. Thus, collectively, these observations demonstrate that the BVSC reporter enables the efficient monitoring of the specification, migration, and further differentiation of PGCs in vivo.

\section{Germ line-competent ES cells bearing the BVSC transgenes}

We derived ES cell lines from the blastocysts from BDF1 females mated with the BVSC males. The undifferentiated BVSC ES cells cultured in the ES cell maintenance medium (see Materials and Methods) showed neither Prdm1mVenus nor Dppa3-ECFP expression (Fig. 5A). To investigate the ability of the BVSC ES cells to contribute to the germ line, we generated diploid chimeras and observed their contribution to the developing germ cell lineage. At E9.5, we detected a good contribution of the ES cells throughout the entire embryo and to the migrating PGCs in the hindgut endoderm: a majority of the migrating PGCs expressed BVSC transgenes (Fig. 5B). AtE13.5, the ES cells also contributed substantially to the embryos, showing Prdm1-mVenus expression in the mesenchyme
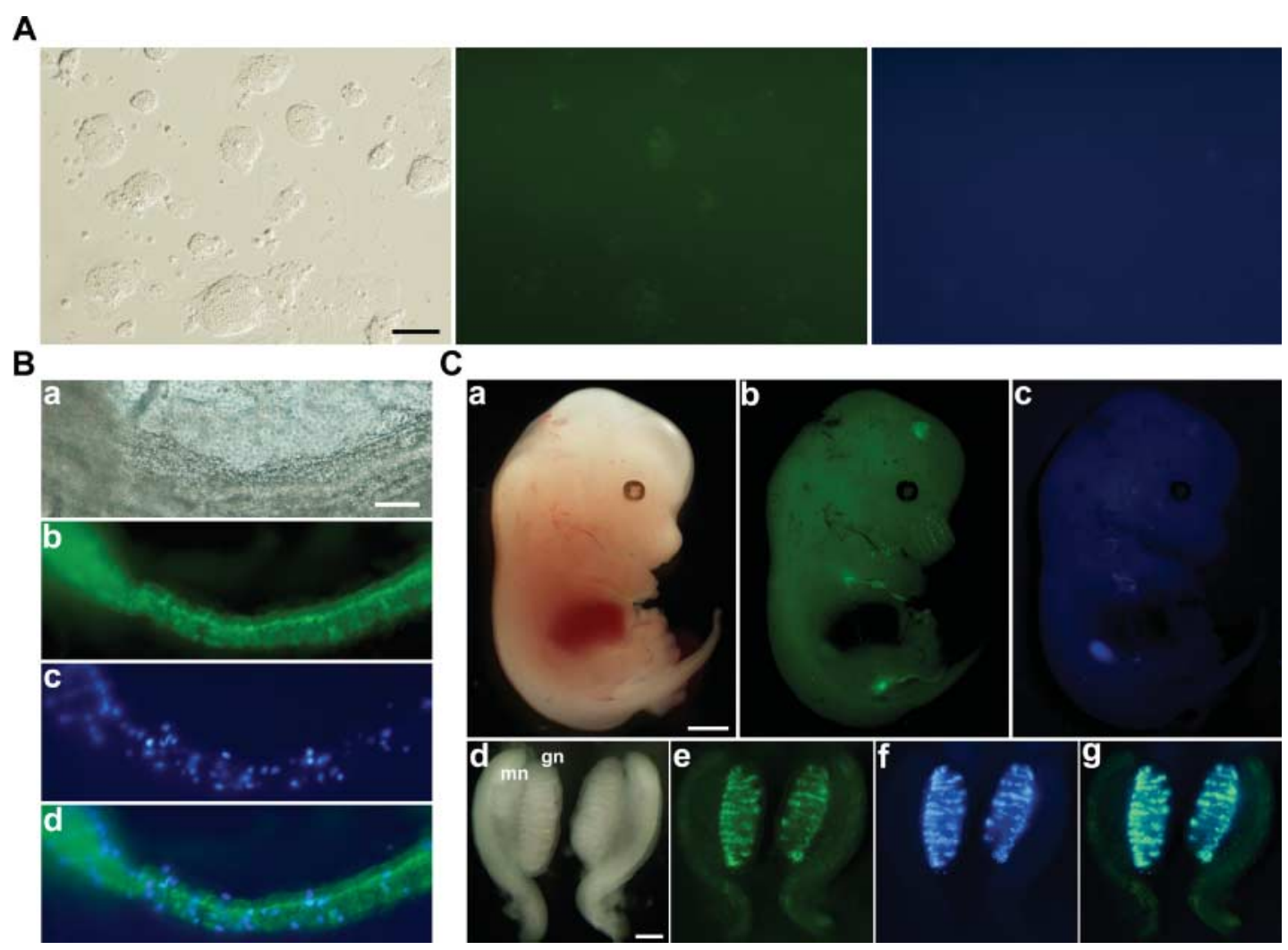

Figure 5 The BVSC ES cells made a robust contribution both to the germ and somatic lineages in diploid chimeras. (A) The BVSC ES cells with bright field images are shown on the left, Prdm1-mVenus expression is shown in the middle, and Dppa3-ECFP expression is shown on the right. Bar, $100 \mu \mathrm{m}$. (B) A BVSC ES cell E9.5 chimera showing high contribution of the BVSC ES cells to the developing gut endoderm and migrating PGCs. (a) bright field image, (b) Prdm1-mVenus expression, (c) Dppa3-ECFP expression, and (d) merged BVSC image. Bar, $50 \mu \mathrm{m}$. (C) A BVSC ES cell E13.5 chimera. (a) Bright field image, (b) Prdm1-mVenus expression, (c) Dppa3-ECFP expression, (d) bright field image of the urogenital region of the same chimera, (e) Prdm1-mVenus expression in (d), (f) Dppa3-ECFP expression in (d), and (g) merged BVSC image in (d). gn, gonad; mn, mesonephros. Bar in (a), $500 \mu \mathrm{m}$; in (d), $150 \mu \mathrm{m}$. 
of the incipient sensory vibrissae and the mesenchyme encompassing the ZPA, recapitulating the endogenous $\operatorname{Prdm} 1$ expression. In the genital ridges, robust expression of BVSC was observed in PGCs (Fig. 5C). Thus, we demonstrated that the BVSC ES cells have the ability to efficiently form germ cells in vivo.

\section{Discussion}

We described here the generation of BVSC transgenic mice that simultaneously monitor endogenous expression of Prdm1 and Dppa3, two key markers for PGCs (Saitou et al. 2002, Sato et al. 2002, Ohinata et al. 2005, Vincent et al. 2005). The BVSC transgenic strain has critical advantages as a germ line reporter over other transgenic lines: it detects the germ cell lineage from its very beginning by Prdm1-mVenus expression and compensates the subsequent relatively widespread expression of Prdm 1 by exclusive germ line expression of Dppa3-ECFP after E8.5. Thus, the BVSC strain is considered to be the first reporter that guarantees efficient and reliable visualization of in vivo germ cells from their incipience to at least their colonization and proliferation in the embryonic gonads, the period in which germ cells exhibit one of the most complicated behaviors in their development (Sasaki \& Matsui 2008). The BVSC transgenic strain provided explicit evidence that $\operatorname{Prdm} 1$ and Dppa3 expression are regulated very differently (Figs $2-5$ ), which is quite relevant in terms of the mechanism of germ cell specification. We detected Dppa3-ECFP expression in PGCs after E8.5, which is $\sim 1$ day after the onset of Dppa3 mRNA expression and slightly later than the stella-EGFP or stella-EGFP BAC transgene expression reported previously (Payer et al. 2006). Nonetheless, very bright fluorescence of ECFP assures easy detection of PGCs after E8.5.

We note that, in some cases, both fluorescent markers, especially Dppa3-ECFP, appeared to show greater stability over the endogenous proteins: for example, endogenous DPPA3 protein expression becomes undetectable after E4.5 (Sato et al. 2002), but we observed persistent fluorescence of Dppa3-ECFP until E5.5 (Fig. 2A and B). Similarly, endogenous DPPA3 is down-regulated after E12.5 in the female genital ridges and becomes undetectable at E16.5 (Sato et al. 2002). However, we detected Dppa3-ECFP fluorescence throughout the development of the embryonic ovary, although it did indeed become weaker and more restricted after E13.5 (Fig. 4D). The half-life of GFP and its variants in vivo is $\sim 24-48 \mathrm{~h}$ (Chalfie \& Kain 2005), and this would depend on when and where they are expressed. Despite these points, the exclusive expression of Dppa3-ECFP in the germ cell lineage ensures its reliability as a germ cell reporter.

We established BVSC ES cells that made an efficient contribution to both the germ and somatic lineages in diploid chimeras. It has been shown that the germ cell fate in mice is induced by BMP signals (Lawson et al. 1999, Ying et al. 2000, Chang \& Matzuk 2001, Tremblay et al. 2001, Ying \& Zhao 2001, Hayashi et al. 2002, Chu et al. 2004) and the specified PGCs repress a somatic program represented by Hox gene expression and regain potential pluripotency as indicated by their Sox2 re-expression (Saitou et al. 2002, Yabuta et al. 2006). It is also notable that, almost immediately after their specification and concomitant with their migration, PGCs have been shown to embark on an ordered reprogramming of their epigenome, which includes the erasure of significant levels of genome-wide DNA methylation and histone $\mathrm{H} 3$-lysine (K) 9 dimethylation, followed by the up-regulation of $\mathrm{H} 3 \mathrm{~K} 27$ trimethylation (Seki et al. 2005, 2007). Quantitative single-cell expression profiling showed that the transitions from Prdm1-positive PGC precursors to Dppa3-positive PGCs and to more advanced migrating PGCs involve a highly dynamic, stage-dependent transcriptional orchestration (Yabuta et al. 2006). Furthermore, a number of gene mutations have been shown to affect PGC development (Mintz \& Russell 1957, McCoshen \& McCallion 1975, Buehr et al. 1993, Beck et al. 1998, Tsuda et al. 2003, Youngren et al. 2005, Covello et al. 2006). Despite these recent critical advances on the genetics of early germ cell development, the underlying biochemical mechanisms remain almost entirely unexplored, mainly because PGCs in vivo, especially at earlier stages, are too small in number for such an analysis. Thus, a precise recapitulation of the PGC specification process and subsequent development using ES cells in culture, which would provide abundant experimental materials, will be an important goal in the relevant fields.

We assume that one of the reasons why it has been difficult to induce functional PGC-like cells from the ES cells may be because most such attempts have used single transgene reporters with germ line expression (reviewed by Daley 2007), despite the fact that the ES cells can potentially up-regulate such single reporters inadequately due to their unique chromatin state (Bernstein et al. 2006, Lee et al. 2006). The use of BVSC ES cells as a starting material and monitoring of the temporally coordinated expression of Prdm1-mVenus and Dppa3-ECFP will circumvent this problem and may serve as a paradigm for this line of exploration.

\section{Materials and Methods}

\section{Generation of Prdm1-mVenus, Dppa3-ECFP, and Dppa3-Venus transgenic mice}

BACs bearing the Prdm1 or Dppa3 genomic locus of the C57BL/6 background were purchased from BACPAC Resources Center (Children's Hospital Oakland Research Institute, Oakland, CA, USA). For preparing Venus (a kind gift from A Miyawaki) targeted to the plasma membrane, the coding sequence of Venus was subcloned after the Igк leader sequence of the pDisplay vector 
(Invitrogen). The resultant sequence from the Igא leader to the bovine growth hormone polyadenylation signal was recombined after the initial in-frame ATG of the exon 3 of the Prdm1 gene by Red/ET recombineering (Gene Bridges, Heidelberg, Germany), according to the protocol provided by the manufacturer. The entire genomic sequence $(\sim 230 \mathrm{~kb})$ was excised by Notl digestion and separated from the vector by gel filtration using CL-4B sepharose (Yang et al. 1997). For construction of the Dppa3-ECFP and Dppa3-Venus transgenes, ECFP (Takara, Tokyo, Japan) or Venus coding sequences including an SV40 polyadenylation sequence were recombined after the initial in-frame ATG of the exon 2 of the Dppa3 gene by Red/ET recombineering. To remove the Gdf3 gene from the transgene, the recombined BAC was digested with Sacll and Smal and an $\sim 16 \mathrm{~kb}$ element encompassing the upstream region, exon 1 , and part of intron 1 of the Dppa3 gene was isolated and subcloned into the Sacll and Smal sites of the pKO919 vector (Lexicon Genetics Incorporated, Woodlands, TX, USA). The sequence from the intron 1 to part of exon 4 including the recombined ECFP or Venus sequence $(\sim 4.6 \mathrm{~kb})$ was then amplified by Pyrobest DNA polymerase (Takara) using 5'-GGTGAAGCCTGTAATCACTGC-3' and 5'-AAAAGCGGCCGCCATCTGAATGGCTCACTGTCC-3' primer pairs and subcloned into the Smal and Notl sites of the pKO919 vector bearing the upstream element. The sequence of the amplified portion was confirmed by DNA sequencing. The entire resultant insert was excised by Ascl and Notl digestion and purified by QIAEX II (Qiagen) using the manufacturer's protocol.

The Prdm1-mVenus, Dppa3-ECFP, and Dppa3-Venus constructs were then injected into pronuclei of B6DBA F2 zygotes to generate transgenic mice, which were genotyped by PCR using the primer pair DisplayF, 5'-ACTCATCTCAGAAGAGGATCTG-3'; DisplayR, 5'-CACAGTCGAGGCTGATCTCG-3' for Prdm 1mVenus and the primer pair SV40F, 5'-CGACTCTAGATCATAATCAGCC-3'; SV40R, 5' -TAAGATACATTGATGAGTTTGGAC-3' for Dppa3-ECFPand Dppa3-Venus. The selected transgenic lines (see Results) were backcrossed onto the $\mathrm{C} 57 \mathrm{BL} / 6$ background at least five times.

\section{Isolation of transgenic embryos, immunofluorescence staining, and imaging}

All the animals were treated with appropriate care according to the RIKEN ethics guidelines. Noon of the day when the vaginal plugs of mated females were identified was scored as E0.5. Female BDF1 mice were mated with male BVSC transgenic mice and were killed at the designated stages to recover embryos. Preimplantation embryos were collected by flushing the oviduct or uteri with M2 medium, and post-implantation embryos were isolated in DMEM with 10\% fetal bovine serum (FBS) (Stem Cell Science, Melbourne, Australia) and $1 \mathrm{mM}$ HEPES. They were imaged immediately thereafter either with an Olympus IX71 upright or SZX16 dissection fluorescent microscope equipped with a DP70 cold CCD camera (Olympus, Tokyo, Japan).

For standard whole-mount immunofluorescence analysis, isolated embryos were fixed in $4 \%$ paraformaldehyde (PFA) in PBS for $4 \mathrm{~h}$ at $4{ }^{\circ} \mathrm{C}$, washed three times with PBS- $0.2 \%$ Triton (PBS-T), and blocked with PBS-T with 2\% normal goat serum (Vector Laboratories, Burlingame, CA) overnight. The embryos were then incubated with primary antibodies (anti-POU5F1
(1:500, rabbit polyclonal, a kind gift of H Hamada; Shimazaki et al. 1993), anti-DPPA3 (1:1000, rabbit polyclonal; Seki et al. 2007), and anti-GFP (1:500, rat monoclonal, Nakarai, Kyoto, Japan)) in blocking solution for $96 \mathrm{~h}$ at $4{ }^{\circ} \mathrm{C}$, washed eight times with PBS-T, incubated with secondary antibodies (1:500, Alexa Fluor 488 goat anti-rat IgG and Alexa Fluor 568 anti-rabbit IgG (Invitrogen)), and DAPI for $48 \mathrm{~h}$ at $4^{\circ} \mathrm{C}$ in blocking solution, washed eight times with PBS-T, and mounted in Vectashield (Vector Laboratories) for observation by confocal microscopy (LSM 510 META (Zeiss, Jena, Germany)).

For immunostaining of BVSC genital ridges with anti-MVH (DDX4) antibody (rabbit polyclonal; Abcam, Cambridge, UK), isolated genital ridges at E11.5 were fixed in 4\% PFA in PBS for $1 \mathrm{~h}$ at room temperature, washed three times with PBS-T, blocked with PBS-T with $0.5 \%$ normal goat serum for 30 min, incubated with the primary antibody $(1: 250)$ in blocking solution for $1 \mathrm{~h}$, washed three times with PBS-T, incubated with a secondary antibody (1:1000, Alexa Fluor 633 goat antirabbit IgG (Invitrogen)) for $30 \mathrm{~min}$, washed three times with PBS-T, and mounted in Vectashield (Vector Laboratories) for observation by confocal microscopy (LSM 510 META (Zeiss)).

\section{Fluorescence in situ hybridization to determine the chromosomal localization of the transgenes}

To determine the chromosomal localization of the transgenes, the splenocytes were collected from the spleen of the transgenic mice in RPMI 1640 (Invitrogen) supplemented with kanamycin. The isolated splenocytes were cultured in RPMI 1640 supplemented with fetal calf serum (15\%), concanavalin A $(3 \mu \mathrm{g} / \mathrm{ml})$, lipopolysaccharide $(10 \mu \mathrm{g} / \mathrm{ml})$, and $\beta$-mercaptoethanol $\left(5 \times 10^{-5} \mathrm{M}\right)$ for a few days, then for $3.5 \mathrm{~h}$ in the presence of $30 \mu \mathrm{g} / \mathrm{ml}$ bromodeoxyuridine, and an additional $30 \mathrm{~min}$ with $0.02 \mu \mathrm{g} / \mathrm{ml}$ colcemid. The cells were then collected, treated with a hypotonic buffer $(0.075 \mathrm{M} \mathrm{KCl})$, and fixed in methanol with acetic acid (methanol:acetic acid $3: 1$ ), and the chromosomal spreads were prepared on a glass slide. The spreads were air dried for a few days, stained with Hoechst 33258, and irradiated with u.v., and a Hoechst G-band staining pattern was prepared.

The BAC clone bearing the Prdm1 gene or the plasmid bearing Dрpa3 cDNA were labeled with digoxigenin-11-dUTP using a nick translation kit (Invitrogen). The chromosome spreads were denatured in $70 \%$ formamide in $2 \times \mathrm{SSC}$ at $70{ }^{\circ} \mathrm{C}$ for $2 \mathrm{~min}$, washed with $70 \%$ and $100 \%$ ethanol, air dried, and hybridized with the denatured probe cDNAs at $37^{\circ} \mathrm{C}$ overnight. The hybridized chromosomal spreads were washed stringently and the hybridized signals were detected using anti-digoxigenin antibody conjugated with Cy3. The images were obtained by Leica DMRA2 fluorescent microscopy (Leica, Wetzlar, Germany) and analyzed using Leica CW4000 FISH software.

\section{Derivation of transgenic ES cells and generation of chimeras}

The derivation of ES cells from blastocysts was performed essentially as described previously (Wakayama et al. 2001, 2005). Female BDF1 mice were mated with male BVSC transgenic mice and the morulae were flushed out from the 
oviduct or uteri at E2.5 and cultured overnight in KSOM medium. The developed blastocysts were treated with acid Tyrode's solution to remove the zona pellucida, and each blastocyst was seeded onto mouse embryonic feeder cells in ES cell derivation medium (Knockout DMEM (Invitrogen) with $2 \mathrm{mM}$ L-glutamine (Invitrogen), $1 \times$ MEM non-essential amino acids (0.1 mM; Invitrogen), $1 \times$ nucleosides $(0.03 \mathrm{mM}$ each; Chemicon, Temecula, CA, USA), $1 \times \beta$-mercaptoethanol $(0.1 \mathrm{mM}$; ChemiCon), $2 \times 10^{3}$ units/ml leukemia inhibitory factor (LIF; ESGRO; Chemicon), and 20\% KSR (Invitrogen)) in a 96-well plate and cultured at $37^{\circ} \mathrm{C}$ under $5 \% \mathrm{CO}_{2}$ until the ICM cells had grown sufficiently ( $\sim 10$ days). The developed cells were passaged in ES cell maintenance medium (knockout DMEM with $2 \mathrm{mM}$ L-glutamine, $1 \times$ MEM non-essential amino acids, $1 \times$ nucleosides, $1 \times \beta$-mercaptoethanol, $1 \times 10^{3}$ units $/ \mathrm{ml} \mathrm{LIF}$, and $20 \%$ FBS (Stem Cell Science)) under a feeder-free condition, and undifferentiated ES cells were eventually established. Generation of diploid chimeras was performed with a standard protocol using C57BL/6 blastocysts as recipients.

\section{Declaration of interest}

The authors declare that there is no conflict of interest that could be perceived as prejudicing the impartiality of the research reported.

\section{Funding}

$\mathrm{YO}$ is a fellow in the Special Postdoctoral Researchers Program of RIKEN. This study was supported in part by a Grant-in-Aid from the Ministry of Education, Culture, Sports, Science, and Technology of Japan, and by a PRESTO project grant from the Japan Science and Technology Agency.

\section{Acknowledgements}

We thank $\mathrm{H}$ Hamada for the anti-POU5F1 antibody and A Miyawaki for the Venus plasmid.

\section{References}

Anderson R, Copeland TK, Scholer H, Heasman J \& Wylie C 2000 The onset of germ cell migration in the mouse embryo. Mechanisms of Development 91 61-68.

Baxendale S, Davison C, Muxworthy C, Wolff C, Ingham PW \& Roy S 2004 The B-cell maturation factor Blimp-1 specifies vertebrate slow-twitch muscle fiber identity in response to Hedgehog signaling. Nature Genetics 36 88-93.

Beck AR, Miller IJ, Anderson P \& Streuli M 1998 RNA-binding protein TIAR is essential for primordial germ cell development. PNAS 95 2331-2336.

Bernstein BE, Mikkelsen TS, Xie X, Kamal M, Huebert DJ, Cuff J, Fry B, Meissner A, Wernig M, Plath K et al. 2006 A bivalent chromatin structure marks key developmental genes in embryonic stem cells. Cell 125 315-326.

Buehr M, McLaren A, Bartley A \& Darling S 1993 Proliferation and migration of primordial germ cells in We/We mouse embryos. Developmental Dynamics 198 182-189.

Capel B 2000 The battle of the sexes. Mechanisms of Development 92 89-103.

Chalfie M \& Kain SR 2005 Green Fluorescent Protein: Properties, Applications and Protocols (Methods of Biochemical Analysis). New York: Wiley-Liss.
Chang H \& Matzuk MM 2001 Smad5 is required for mouse primordial germ cell development. Mechanisms of Development 104 61-67.

Chang DH, Cattoretti G \& Calame KL 2002 The dynamic expression pattern of B lymphocyte induced maturation protein-1 (Blimp-1) during mouse embryonic development. Mechanisms of Development 117 305-309.

Chiquoine AD 1954 The identification, origin and migration of the primordial germ cells in the mouse embryo. Anatomical Record 118 135-146.

Chu GC, Dunn NR, Anderson DC, Oxburgh L \& Robertson EJ 2004 Differential requirements for Smad4 in TGFbeta-dependent patterning of the early mouse embryo. Development 131 3501-3512.

Covello KL, Kehler J, Yu H, Gordan JD, Arsham AM, Hu CJ, Labosky PA, Simon MC \& Keith B 2006 HIF-2alpha regulates Oct-4: effects of hypoxia on stem cell function, embryonic development, and tumor growth. Genes and Development 20 557-570.

Daley GQ 2007 Gametes from embryonic stem cells: a cup half empty or half full? Science 316 409-410.

Ginsburg M, Snow MH \& McLaren A 1990 Primordial germ cells in the mouse embryo during gastrulation. Development 110 521-528.

Hayashi K, Kobayashi T, Umino T, Goitsuka R, Matsui Y \& Kitamura D 2002 SMAD1 signaling is critical for initial commitment of germ cell lineage from mouse epiblast. Mechanisms of Development 118 99-109.

Hayashi K, de Sousa Lopes SM \& Surani MA 2007 Germ cell specification in mice. Science 316 394-396.

Hernandez-Lagunas L, Choi IF, Kaji T, Simpson P, Hershey C, Zhou Y, Zon L, Mercola M \& Artinger KB 2005 Zebrafish narrowminded disrupts the transcription factor prdm 1 and is required for neural crest and sensory neuron specification. Developmental Biology 278 347-357.

Horsley V, O'Carroll D, Tooze R, Ohinata Y, Saitou M, Obukhanych T, Nussenzweig M, Tarakhovsky A \& Fuchs E 2006 Blimp1 defines a progenitor population that governs cellular input to the sebaceous gland. Cell 126 597-609.

Kallies A, Hawkins ED, Belz GT, Metcalf D, Hommel M, Corcoran LM, Hodgkin PD \& Nutt SL 2006 Transcriptional repressor Blimp-1 is essential for T cell homeostasis and self-tolerance. Nature Immunology 7 466-474.

Lawson KA, Dunn NR, Roelen BA, Zeinstra LM, Davis AM, Wright CV, Korving JP \& Hogan BL 1999 Bmp4 is required for the generation of primordial germ cells in the mouse embryo. Genes and Development 13 424-436.

Lee TI, Jenner RG, Boyer LA, Guenther MG, Levine SS, Kumar RM, Chevalier B, Johnstone SE, Cole MF, Isono K et al. 2006 Control of developmental regulators by Polycomb in human embryonic stem cells. Cell 125 301-313.

MacGregor GR, Zambrowicz BP \& Soriano P 1995 Tissue non-specific alkaline phosphatase is expressed in both embryonic and extraembryonic lineages during mouse embryogenesis but is not required for migration of primordial germ cells. Development 121 1487-1496.

Magnusdottir E, Kalachikov S, Mizukoshi K, Savitsky D, Ishida-Yamamoto A, Panteleyev AA \& Calame K 2007 Epidermal terminal differentiation depends on B lymphocyte-induced maturation protein-1. PNAS 104 14988-14993.

Martins GA, Cimmino L, Shapiro-Shelef $M$, Szabolcs M, Herron A, Magnusdottir E \& Calame K 2006 Transcriptional repressor Blimp-1 regulates $\mathrm{T}$ cell homeostasis and function. Nature Immunology 7 457-465.

Matsui Y, Zsebo K \& Hogan BL 1992 Derivation of pluripotential embryonic stem cells from murine primordial germ cells in culture. Cell $\mathbf{7 0}$ 841-847.

McCoshen JA \& McCallion DJ 1975 A study of the primordial germ cells during their migratory phase in Steel mutant mice. Experientia 31 589-590.

Mintz B \& Russell ES 1957 Gene-induced embryological modifications of primordial germ cells in the mouse. Journal of Experimental Zoology 134 $207-237$.

Nagai T, Ibata K, Park ES, Kubota M, Mikoshiba K \& Miyawaki A 2002 A variant of yellow fluorescent protein with fast and efficient maturation for cell-biological applications. Nature Biotechnology 20 87-90.

Ohinata Y, Payer B, O'Carroll D, Ancelin K, Ono Y, Sano M, Barton SC, Obukhanych T, Nussenzweig M, Tarakhovsky A et al. 2005 Blimp1 is a critical determinant of the germ cell lineage in mice. Nature 436 207-213.

Ohinata Y, Seki Y, Payer B, O'Carroll D, Surani MA \& Saitou M 2006 Germline recruitment in mice: a genetic program for epigenetic reprogramming. Ernst Schering Research Foundation Workshop 60 143-174. 
Payer B, Saitou M, Barton SC, Thresher R, Dixon JP, Zahn D, Colledge WH, Carlton MB, Nakano T \& Surani MA 2003 Stella is a maternal effect gene required for normal early development in mice. Current Biology 13 $2110-2117$

Payer B, Chuva de Sousa Lopes SM, Barton SC, Lee C, Saitou M \& Surani MA 2006 Generation of stella-GFP transgenic mice: a novel tool to study germ cell development. Genesis 44 75-83.

Pepling ME 2006 From primordial germ cell to primordial follicle: mammalian female germ cell development. Genesis 44 622-632.

Robertson EJ, Charatsi I, Joyner CJ, Koonce CH, Morgan M, Islam A, Paterson C, Lejsek E, Arnold SJ, Kallies A et al. 2007 Blimp1 regulates development of the posterior forelimb, caudal pharyngeal arches, heart and sensory vibrissae in mice. Development 134 4335-4345.

Roy S \& Ng T 2004 Blimp-1 specifies neural crest and sensory neuron progenitors in the zebrafish embryo. Current Biology 14 1772-1777.

Saitou M, Barton SC \& Surani MA 2002 A molecular programme for the specification of germ cell fate in mice. Nature 418 293-300.

Sasaki H \& Matsui Y 2008 Epigenetic events in mammalian germ-cell development: reprograming and beyond. Nature Reviews. Genetics 9 129-140.

Sato M, Kimura T, Kurokawa K, Fujita Y, Abe K, Masuhara M, Yasunaga T, Ryo A, Yamamoto M \& Nakano T 2002 Identification of PGC7, a new gene expressed specifically in preimplantation embryos and germ cells. Mechanisms of Development 113 91-94.

Seki Y, Hayashi K, Itoh K, Mizugaki M, Saitou M \& Matsui Y 2005 Extensive and orderly reprogramming of genome-wide chromatin modifications associated with specification and early development of germ cells in mice. Developmental Biology 278 440-458.

Seki Y, Yamaji M, Yabuta Y, Sano M, Shigeta M, Matsui Y, Saga Y, Tachibana M, Shinkai Y \& Saitou M 2007 Cellular dynamics associated with the genome-wide epigenetic reprogramming in migrating primordial germ cells in mice. Development 134 2627-2638.

Seydoux G \& Braun RE 2006 Pathway to totipotency: lessons from germ cells. Cell 127 891-904.

Shapiro-Shelef M, Lin KI, McHeyzer-Williams LJ, Liao J, McHeyzerWilliams MG \& Calame K 2003 Blimp-1 is required for the formation of immunoglobulin secreting plasma cells and pre-plasma memory B cells. Immunity 19 607-620.

Shimazaki T, Okazawa H, Fujii H, Ikeda M, Tamai K, McKay RD, Muramatsu M \& Hamada H 1993 Hybrid cell extinction and re-expression of Oct-3 function correlates with differentiation potential. EMBO Journal 12 4489-4498.

de Souza FS, Gawantka V, Gomez AP, Delius H, Ang SL \& Niehrs C 1999 The zinc finger gene Xblimp1 controls anterior endomesodermal cell fate in Spemann's organizer. EMBO Journal 18 6062-6072.

Tajbakhsh S \& Buckingham M 2000 The birth of muscle progenitor cells in the mouse: spatiotemporal considerations. Current Topics in Developmental Biology 48 225-268.

Tanaka SS, Toyooka Y, Akasu R, Katoh-Fukui Y, Nakahara Y, Suzuki R, Yokoyama M \& Noce T 2000 The mouse homolog of Drosophila Vasa is required for the development of male germ cells. Genes and Development 14 841-853.

Tanaka SS, Nagamatsu G, Tokitake Y, Kasa M, Tam PP \& Matsui Y 2004 Regulation of expression of mouse interferon-induced transmembrane protein like gene-3, Ifitm3 (mil-1, fragilis), in germ cells. Developmental Dynamics 230 651-659.

Toyooka Y, Tsunekawa N, Takahashi Y, Matsui Y, Satoh M \& Noce T 2000 Expression and intracellular localization of mouse Vasa-homologue protein during germ cell development. Mechanisms of Development 93 139-149.
Toyooka Y, Tsunekawa N, Akasu R \& Noce T 2003 Embryonic stem cells can form germ cells in vitro. PNAS 100 11457-11462.

Tremblay KD, Dunn NR \& Robertson EJ 2001 Mouse embryos lacking Smad1 signals display defects in extra-embryonic tissues and germ cell formation. Development 128 3609-3621.

Tsuda M, Sasaoka Y, Kiso M, Abe K, Haraguchi S, Kobayashi S \& Saga Y 2003 Conserved role of nanos proteins in germ cell development. Science 301 1239-1241.

Turner CA Jr, Mack DH \& Davis MM 1994 Blimp-1, a novel zinc fingercontaining protein that can drive the maturation of B lymphocytes into immunoglobulin-secreting cells. Cell 77 297-306.

Vincent SD, Dunn NR, Sciammas R, Shapiro-Shalef M, Davis MM, Calame K, Bikoff EK \& Robertson EJ 2005 The zinc finger transcriptional repressor Blimp1/Prdm1 is dispensable for early axis formation but is required for specification of primordial germ cells in the mouse. Development 132 1315-1325.

Wakayama T, Tabar V, Rodriguez I, Perry AC, Studer L \& Mombaerts P 2001 Differentiation of embryonic stem cell lines generated from adult somatic cells by nuclear transfer. Science 292 740-743.

Wakayama S, Mizutani E, Kishigami S, Thuan NV, Ohta H, Hikichi T, Bui HT, Miyake M \& Wakayama T 2005 Mice cloned by nuclear transfer from somatic and ntES cells derived from the same individuals. Journal of Reproduction and Development 51 765-772.

Wilm TP \& Solnica-Krezel L 2005 Essential roles of a zebrafish prdm1/blimp1 homolog in embryo patterning and organogenesis. Development 132 393-404.

Yabuta Y, Kurimoto K, Ohinata Y, Seki Y \& Saitou M 2006 Gene expression dynamics during germline specification in mice identified by quantitative single-cell gene expression profiling. Biology of Reproduction $\mathbf{7 5}$ 705-716.

Yang XW, Model P \& Heintz N 1997 Homologous recombination based modification in Escherichia coli and germline transmission in transgenic mice of a bacterial artificial chromosome. Nature Biotechnology 15 859-865.

Yeom YI, Fuhrmann G, Ovitt CE, Brehm A, Ohbo K, Gross M, Hubner K \& Scholer HR 1996 Germline regulatory element of Oct-4 specific for the totipotent cycle of embryonal cells. Development 122 881-894.

Ying Y \& Zhao GQ 2001 Cooperation of endoderm-derived BMP2 and extraembryonic ectoderm-derived BMP4 in primordial germ cell generation in the mouse. Developmental Biology 232 484-492.

Ying Y, Liu XM, Marble A, Lawson KA \& Zhao GQ 2000 Requirement of Bmp8b for the generation of primordial germ cells in the mouse. Molecular Endocrinology 14 1053-1063.

Yoshimizu T, Sugiyama N, De Felice M, Yeom YI, Ohbo K, Masuko K, Obinata M, Abe K, Scholer HR \& Matsui Y 1999 Germline-specific expression of the Oct-4/green fluorescent protein (GFP) transgene in mice. Development, Growth and Differentiation 41 675-684.

Youngren KK, Coveney D, Peng X, Bhattacharya C, Schmidt LS, Nickerson ML, Lamb BT, Deng JM, Behringer RR, Capel B et al. 2005 The Ter mutation in the dead end gene causes germ cell loss and testicular germ cell tumours. Nature 435 360-364.

Received 3 February 2008

First decision 14 March 2008

Revised manuscript received 12 May 2008

Accepted 25 June 2008 